\title{
When measurements are misleading: modelling the effects of blood pressure misclassification in the English population
}

Tom Marshall
Guidelines recommend that primary care teams measure their adult patients' blood pressures. ${ }^{1}$ Is this always a useful activity? A measurement of blood pressure is an estimate of the true mean blood pressure. Clinical decisions are based on the average of several measurements. However, measurement is imperfect, and blood pressure shows random biological variation from beat to beat. Because of this unavoidable variation patients may be misclassified as above or below the treatment threshold. Thus, like any diagnostic or screening test, estimation of blood pressure is subject to false positives and false negatives. The proportion of test positives that are true positives is the positive predictive value of a test: an index of the test's precision. This paper calculates positive predictive values for blood pressure measurement in an English population.

\section{Methods and results}

A secondary analysis of a large dataset of individual patients' blood pressures yielded an estimate of intra-individual blood pressure variation between clinic visits. The dataset had been obtained by combining individual patient data from randomised controlled trials of blood pressure treatment. Intra-individual measurements of systolic blood pressure have a coefficient of variation of $9.9 \%$ and of diastolic blood pressure of $9.2 \%{ }^{2}$ (V. Musini, personal communication, 21 July 2003). These estimates can be applied across the study population because the coefficient of variation changes little with age or sex. ${ }^{3}$ A decision to treat raised blood pressure should be based on the mean of three estimations of blood pressure. ${ }^{1}$ The coefficient of variation of an estimate of blood pressure based on the mean of three measurements is therefore $5.7 \% \quad(5.7 \%=9.9 \% / \sqrt{ } 3)$ for systolic and $5.3 \%$ $(5.3 \%=9.2 \% / \sqrt{ } 3)$ for diastolic blood pressure.

Combined data from the health survey for England of 1998, 1999, and 2000 provided a dataset of 13284 people with complete information on cardiovascular risk factors. ${ }^{4}$ I used the Framingham risk equation to calculate individual 10 year coronary risks for each of these persons. ${ }^{5}$ On an MS Excel spreadsheet I generated an error term for each individual patient's systolic and diastolic blood pressures. Error terms were normally distributed, with a coefficient of variation equivalent to that obtained from the mean of three blood pressure measurements. In addition to their true blood pressure and true coronary risk I thus allocated to individual patients an estimated systolic and diastolic blood pressure and an estimated coronary risk, each incorporating an error term.

Patients are true positives (eligible for treatment) if their true blood pressure and true coronary risk exceed treatment thresholds based on current British guidelines. These are either blood pressure over 160/100 mm Hg (diastolic or systolic) or blood pressure over 140/90 $\mathrm{mm} \mathrm{Hg}$ with 10 year coronary risk exceeding 15\%. ${ }^{1}$ Patients are test positives if their estimated blood pressure and coronary risk exceed treatment thresholds. I calculated positive predictive values for each group by age and sex.

Positive predictive values for blood pressure estimation are highest in older age groups and lowest in younger age groups (table 1). Of 36 men aged 16-34 classified as needing treatment, only 11 are true positives-a positive predictive value of $31 \%(95 \%$ confidence interval $16 \%$ to $46 \%$ ). Of 19 women $16-34$ classified as needing treatment, five are true positives-a positive predictive value of $26 \%$ (95\% confidence interval $7 \%$ to $46 \%$ ). The positive predictive value of blood pressure estimation for men and women aged $16-35$ combined is $29 \%$ ( $17 \%$ to $41 \%$ ).

\section{Comment}

Routine measurement of blood pressure in persons under 35 is more likely to misdiagnose than to diagnose hypertension correctly. As 10 year coronary risk rarely exceeds $5 \%$ in adults under 35 clinicians should diagnose hypertension with caution-perhaps at a higher threshold. Blood pressure measurement is useful mainly in people with specific indications or coronary risk factors.

Contributor: TM obtained the data, carried out the analysis, and wrote the paper.

Funding: None.

Competing interests: None declared.

Wood D, Durrington P, Poulter N, McInnes G, Rees A, Wray R. Joint British recommendations on prevention of coronary heart disease in clinical ish recommendations on prevention of
practice. Heart 1998;80(suppl 2):S1-29.

2 Wright JM, Musini VJ. Blood pressure variability: lessons learned from a systematic review. Poster presentation D20, 8th International Cochrane Colloquium, Cape Town, October 2000.

3 Hypertension Detection and Follow-up Program Co-operative Group. Variability of blood pressure and the results of screening in the hypertension detection and follow-up program. J Chronic Dis 1978; 31:651-67.

4 Department of Health. Health survey for England 1998; 1999; 2000. www.data-archive.ac.uk (accessed 25 Feb 2003).

5 Anderson KA, Wilson PWF, Odell PM, Kannel WB. An updated coronary risk profile. A statement for health professionals. Circulation 1991;83: 356-62.

True prevalence of eligibility for antihypertensive treatment and positive predictive values based on the mean of three blood pressure measurements

\begin{tabular}{|c|c|c|c|c|}
\hline \multirow[b]{2}{*}{ Age in years } & \multicolumn{2}{|c|}{$\begin{array}{l}\text { True prevalence of eligibility for } \\
\text { antihypertensive treatment (\%) }\end{array}$} & \multicolumn{2}{|c|}{$\begin{array}{l}\text { Positive predictive value of the mean of } \\
\text { three blood pressure measurements (\%) }\end{array}$} \\
\hline & Men & Women & Men & Women \\
\hline 16-34 & 0.9 & 0.3 & 31 & 26 \\
\hline $35-44$ & 4.4 & 1.4 & 62 & 60 \\
\hline $45-54$ & 17.0 & 8.3 & 86 & 79 \\
\hline 55-64 & 38.6 & 22.4 & 93 & 83 \\
\hline $65-74$ & 45.2 & 35.6 & 94 & 83 \\
\hline $75+$ & 45.3 & 36.4 & 87 & 94 \\
\hline
\end{tabular}

Source: Health survey for England 1998, 1999, 2000. ${ }^{4}$

Department of Public Health and Epidemiology, University of Birmingham, Birmingham B15 2TT

Tom Marshall lecturer in public health

T.P.Marshall@ bham.ac.uk

BMJ 2004;328:933
(Accepted 21 October 2003) 